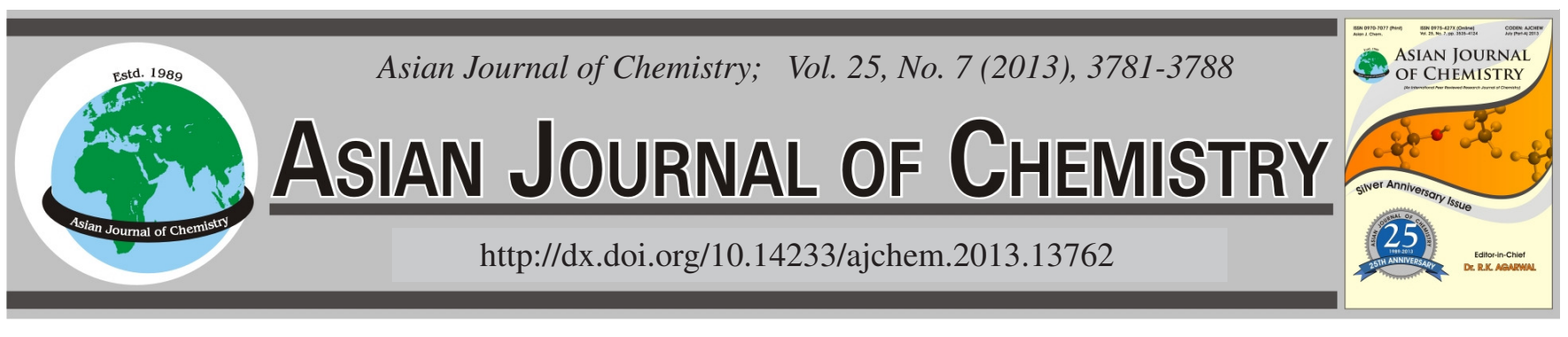

\title{
Inhibition of Pitting Corrosion of the Stainless Steel by Dipyridinium Salts
}

\author{
A.Y. Obaid, S.A. Al-ThabatTI, A.H. Qusti and A.A. Hermas ${ }^{*}$
}

${ }^{1}$ Department of Chemistry, Faculty of Science, King Abdulaziz University, Jeddah, Saudi Arabia

${ }^{2}$ Department of Chemistry, Faculty of Science, Assiut University, Assiut, Egypt

*Corresponding author: Fax: +966 2 6952292; Tel: +966 2 6751355; E-mail: hagag_99@yahoo.com

Key Words: Adsorption, Dipyridinium salts, Corrosion inhibition, Stainless steel, EIS.

\section{INTRODUCTION}

Stainless steels belong to a class of metal and alloys which protect themselves by forming passive film on their surface. However, in an environment with the presence of chloride ions, localized corrosion such as pitting and crevice corrosion is still a serious problem for this type of steel. For this reason, the research study for the passive film of stainless steels and their stability particularly in chloride solutions has a technological importance ${ }^{1}$.

The use of inhibitor is one of the most practical methods for protection of different metals and alloys ${ }^{2,3}$ against the corrosion but few compounds can be applied usefully against the pitting corrosion ${ }^{4}$. The mechanism of corrosion inhibition by organic molecules is mostly attributed due to their adsorption onto metallic surfaces. The adsorption phenomenon depends, principally, on the chemical composition and structure of the inhibitors, nature of the metallic surface and the acidic properties of the medium where the inhibitor-surface interaction takes place ${ }^{5}$.

Surfactants, which consist of one polar group (hydrophilic) and one hydrophobic moiety have been used for several occasions by a large number of investigators and reported that surfactants acts as a good corrosion inhibitors ${ }^{6-14}$. Popova et $a l^{6,7}$, investigated four quaternary ammonium bromides of different heterocyclic compounds as corrosion inhibitors of mild steel in $1 \mathrm{M} \mathrm{HCl}$ and $1 \mathrm{M} \mathrm{H}_{2} \mathrm{SO}_{4}$. Viologens (N,N'- diquaternized 4,4'-dipyridinium salts), which have been employed as herbicides, redox mediators, electrochromic materials, electron-transfer quenchers and as redox probes in self-assembled monolayers ${ }^{15,16}$, could be used as efficient corrosion inhibitors ${ }^{17,18}$. However, the details of dipyridinium dihalides role in the corrosion of stainless steel are not yet known. The purpose of this article is to investigate the effect of three substituted dipyridinium dihalides on the pitting corrosion of the stainless steel in acidic chloride medium. Potentiodynamic polarization, electrochemical impedance (EIS) measurements and optical microscopic investigation were employed.

\section{EXPERIMENTAL}

Three dipyridinium dihalide derivatives with chemical structure as shown in Fig. 1 were synthesized as described else where ${ }^{18}$. A standard corrosion glass cell was used for the polarization and impedance measurements. The material of the working electrode is a sheet with area $1 \mathrm{~cm}^{2}$ from ferritic type 430 stainless steel, it was cut from cold rolled annealed sheet (produced by Nilaco, Japan and containing 17-18.5\% chromium and $<1500 \mathrm{ppm}$ carbon). The counter and reference electrodes are platinum sheet and silver-silver chloride (Ag/ $\mathrm{AgCl}$, saturated $\mathrm{KCl}$ ), respectively.

General procedure: Prior to each experiment the working electrode was wet polished with emery papers up to grade 600 , rinsed with bi-distilled water, acetone, bi-distilled water 


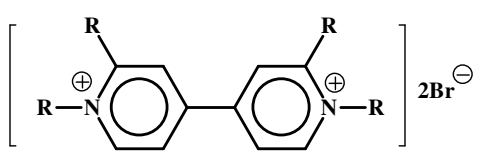

1,1',2,2'-Tetramethyl-4,4'-dipyridinium dibromide ( $\left.\mathrm{TMdPyBr}_{2}\right)$

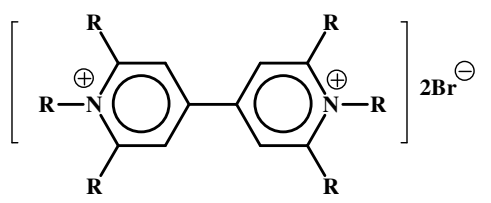

1,1',2,2',6,6'-Hexamethyl-4,4'-dipyridinium dibromide (HMdPyBr

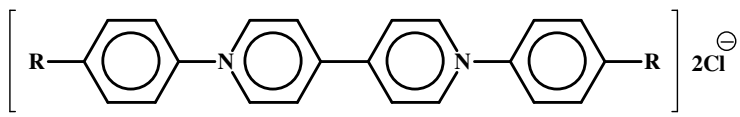

1,1'-Bis(4-methylphenyl)-4,4'-dipyridinium dichloride ( $\left.\mathrm{MPhdPyCl}_{2}\right)$

Fig. 1. Structure of dipyridinium dihalide derivatives $\left(\mathrm{R}=\mathrm{CH}_{3}\right)$

and left in air for $0.5 \mathrm{~h}$. Then, it was transferred to the glass cell which was filled by $200 \mathrm{~mL}$ of $0.1 \mathrm{M} \mathrm{HCl}$ solution. The electrolyte solution was prepared from concentrated analytical reagent $\mathrm{HCl}$ and bi-distilled water. The inhibitor solution was prepared by dissolving the appropriate weight in $0.1 \mathrm{M} \mathrm{HCl}$ solution. All experiments were conducted thermostatically at a given temperature and in an aerated condition without stirring.

Detection method: Electrochemical experiments were recorded using a potentiostat of type Autolab PGSTAT30, coupled to a computer equipped with GPES software for potential and polarization measurements and FRA software for EIS measurement. Potentiodynamic measurements were performed with $0.001 \mathrm{~V} \mathrm{~s}^{-1}$. EIS measurements were conducted potentiostatically at open circuit potential $\left(\mathrm{E}_{\mathrm{cor}}\right)$ with $10 \mathrm{mV}$ rms with frequency range $50 \mathrm{kHz}$ to $0.1 \mathrm{~Hz}$. Microscopic investigation of the electrode surface in absence and presence of the inhibitor was performed by ZEISS optical microscope of type Stemi 2000-C and connected with Digital Canon Camera and computer.

\section{RESULTS AND DISCUSSION}

Corrosion potential measurement: After immersion the working electrode in the polarization cell, $\mathrm{E}_{\mathrm{cor}}$ was recorded versus time for $c a .0 .5 \mathrm{~h}$. The average value for $\mathrm{E}_{\mathrm{cor}}$ of the stainless steel in $0.1 \mathrm{M} \mathrm{HCl}$ at $30^{\circ} \mathrm{C}$ was $0.508 \mathrm{~V}(\mathrm{Ag} / \mathrm{AgCl})$. The shifts of $\mathrm{E}_{\mathrm{cor}}$ from the blank value caused by various concentrations of the studied compounds are shown in Table1. Addition of any inhibitor from the three investigated compounds caused systematic displacement of the potential in the anodic direction, indicating that the anodic reaction is somewhat more inhibited than the cathodic reaction. The shift of $\mathrm{E}_{\text {cor }}$ at any concentration increased in the order $\mathrm{MPhdPyCl}_{2}$ $<\mathrm{TMdPyBr}_{2}<\mathrm{HMdPyBr}_{2}$.

Polarization measurement: Cathodic polarization and anodic polarization to a potential slightly more positive than the primary passive potential $\left(\mathrm{E}_{\mathrm{pp}}\right)$ were carried out in $0.1 \mathrm{M}$ $\mathrm{HCl}$ at $30^{\circ} \mathrm{C}$ and in presence of various concentrations $(5 \times$ $10^{-5}-1 \times 10^{-3} \mathrm{M}$ ) of the inhibitors. Fig. 2 shows representative polarization curves in the absence and presence of $\mathrm{HMdPyBr}_{2}$. Values of corrosion current density $\left(i_{\text {cor }}\right)$ associated with the polarization curves were calculated by extrapolation of both anodic and cathodic branches (within Tafel regions) back to $\mathrm{E}_{\text {cor }}$. The critical current density ( $\left.\mathrm{i}_{\text {crit }}\right)$ which corresponds to the $\mathrm{E}_{\mathrm{pp}}$ was also obtained. It is a criterion for surface oxide formability on the stainless steel. The estimated parameters were recorded in Table-1. Although the positive shift of $\mathrm{E}_{\mathrm{cor}}$, both anodic and cathodic branches shifted to lower current density by addition of the inhibitors indicating inhibition of both the cathodic and anodic reactions. The investigated compounds most likely are mixed type inhibitors with dominant anodic, particularly for $\mathrm{HMdPyBr}_{2}$. The shifting in the polarization curves runs parallel to that of the blank solution. So that, the addition of inhibitor may does not alter the mechanism of either hydrogen evolution or steel dissolution. It was also observed that these inhibitors decreased significantly $i_{\text {crit }}$ and didn't affect on $\mathrm{E}_{\mathrm{pp}}$ of the steel except slight positive shift at high concentrations of $\mathrm{HMdPyBr}_{2}$ and $\mathrm{MPhdPyCl}_{2}$.

From the $i_{\text {cor }}$ values the inhibition efficiency (IE) of the additives was calculated according to:

$$
\mathrm{IE}=\left\{\frac{\left[\mathrm{i}_{\text {cor }}^{\mathrm{o}}-\mathrm{i}_{\text {cor }}\right]}{\mathrm{i}_{\text {cor }}^{\mathrm{o}}}\right\} \times 100
$$

where $i_{\text {cor }}^{\mathbf{o}}$ and $i_{\text {cor }}$ are corrosion current densities in the absence and presence of the inhibitor, respectively. By replacing

\begin{tabular}{|c|c|c|c|c|c|c|c|}
\hline \multicolumn{8}{|c|}{$\begin{array}{c}\text { TABLE-1 } \\
\text { EFFECT OF INHIBITOR CONCENTRATION ON THE POLARIZATION PARAMETERS }\end{array}$} \\
\hline \multirow[t]{2}{*}{ Inhibitor } & $\begin{array}{l}\text { Solution } \\
(\mathrm{M})\end{array}$ & $\begin{array}{c}\text { bc } \\
(\mathrm{mV} / \text { decade })\end{array}$ & $\begin{array}{c}\text { ba } \\
(\mathrm{mV} / \text { decade }) \\
\end{array}$ & $\begin{array}{c}-\mathrm{E}_{\text {cor }} \\
(\mathrm{V})\end{array}$ & $\begin{array}{c}\mathrm{i}_{\mathrm{cor}} \\
\left(\mu \mathrm{A} \mathrm{cm}^{-2}\right)\end{array}$ & $\begin{array}{l}-\mathrm{E}_{\mathrm{pp}} \\
(\mathrm{V})\end{array}$ & $\begin{array}{c}\mathrm{i}_{\text {crit }} \\
\left(\mu \mathrm{A} \mathrm{cm}^{-2}\right)\end{array}$ \\
\hline & Pure & 90 & 62 & 508 & 599 & 417 & 2568 \\
\hline \multirow{4}{*}{$\mathrm{TMdPyBr}_{2}$} & $5.0 \times 10^{-5}$ & 125 & 60 & 0.503 & 384 & 0.421 & 1887 \\
\hline & $1.0 \times 10^{-4}$ & 130 & 48 & 0.492 & 244 & 0.418 & 1740 \\
\hline & $2.5 \times 10^{-4}$ & 118 & 50 & 0.490 & 221 & 0.414 & 1635 \\
\hline & $1.0 \times 10^{-3}$ & 115 & 40 & 0.483 & 174 & 0.412 & 1289 \\
\hline \multirow{5}{*}{$\mathrm{HMdPyBr}_{2}$} & $5.0 \times 10^{-5}$ & 115 & 66 & 0.495 & 511 & 0.415 & 2452 \\
\hline & $1.0 \times 10^{-4}$ & 143 & 64 & 0.492 & 340 & 0.410 & 1369 \\
\hline & $2.5 \times 10^{-4}$ & 105 & 45 & 0.484 & 226 & 0.415 & 1560 \\
\hline & $5.0 \times 10^{-4}$ & 128 & 40 & 0.480 & 142 & 0.400 & 1307 \\
\hline & $1.0 \times 10^{-3}$ & 111 & 38 & 0.472 & 172 & 0.405 & 1284 \\
\hline \multirow{4}{*}{$\mathrm{MPhdPyCl}_{2}$} & $5.0 \times 10^{-5}$ & 137 & 65 & 0.505 & 397 & 0.411 & 2033 \\
\hline & $2.5 \times 10^{-4}$ & 114 & 66 & 0.498 & 246 & 0.387 & 1704 \\
\hline & $5.0 \times 10^{-4}$ & 101 & 50 & 0.492 & 220 & 0.405 & 1537 \\
\hline & $1.0 \times 10^{-3}$ & 93 & 58 & 0.493 & 240 & 0.406 & 1582 \\
\hline
\end{tabular}




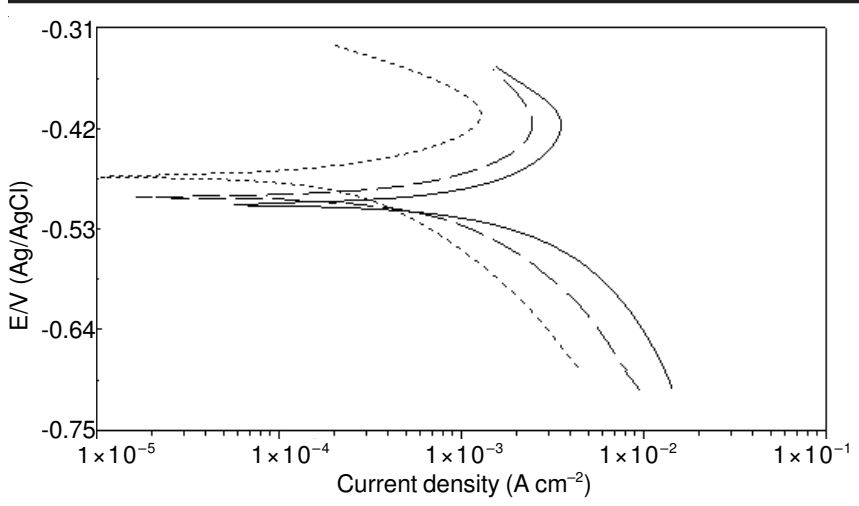

Fig. 2. Cathodic-anodic polarization for the $\mathrm{SS}$ in $0.1 \mathrm{M} \mathrm{HCl} \mathrm{(-)} \mathrm{at} 30^{\circ} \mathrm{C}$ and in presence of $5 \times 10^{-5} \mathrm{M}(--)$ and $1 \times 10^{-3} \mathrm{M}(\cdots) \mathrm{HMdPyBr}_{2}$

$\mathrm{i}_{\text {cor }}$ with $\mathrm{i}_{\text {crit }}$ in the above equation suppression efficiency (SE) of the additives for the active dissolution of the stainless steel was calculated.

Fig. 3A shows the inhibition efficiency against inhibitor concentration. For all inhibitors, the inhibition efficiency increased with increasing the concentration and reached fast to a maximum or plateau. Similar behaviour were observed for the same compounds with carbon steel in sulfuric acid ${ }^{18}$ and other surfactants with steel in $\mathrm{HCl}^{19}$. In presence of the lowest concentration $\left(5 \times 10^{-5} \mathrm{M}\right)$ maximum efficiency was $35.9 \%$ by $\mathrm{TMdPyBr}_{2}$, while it was $77.3 \%$ by $\mathrm{HMdPyBr}_{2}$ at the highest concentration $\left(1 \times 10^{-3} \mathrm{M}\right)$. The results indicate two different arrangements for the inhibitors in the studied concentration range. The inhibition efficiency decreased in the order $\mathrm{TMdPyBr}_{2}>\mathrm{MPhdPyCl}_{2}>\mathrm{HMdPyBr}_{2}$ at the low concentrations, while it decreased in the order $\mathrm{HMdPyBr}_{2}>$ $\mathrm{TMdPyBr}_{2}>\mathrm{MPhdPyCl}_{2}$ at the high concentrations. Fig. 3B shows the supression efficiency against inhibitor concentration. The decreasing of $i_{\text {crit }}$ in presence of the additives was less than that of $i_{\text {cor }}$ but reflects significantly improvement in the passivation of the stainless steel in the acidic chloride solution. The arrangement for the efficiencies of the inhibitors in Fig. 4B is generally similar to that in Fig. 3A.

Effect of temperature: The effects of temperature on the inhibitive action of the studied inhibitors were performed. The electrochemical measurements of stainless steel were carried out in $0.1 \mathrm{M} \mathrm{HCl}$ and in absence and presence of $1 \times 10^{-3} \mathrm{M}$ inhibitor at different temperatures $\left(30-50{ }^{\circ} \mathrm{C}\right)$. Firstly, it is observed that $\mathrm{E}_{\text {cor }}$ of the stainless steel in the pure medium increased with increasing temperature, it shifted from -508 $\mathrm{mV}$ at $30^{\circ} \mathrm{C}$ to $-480 \mathrm{mV}$ at $50{ }^{\circ} \mathrm{C}$. This is attributed to partial suppression of corrosion by accumulation of the corrosion product on the steel surface. In presence of $1 \times 10^{-3} \mathrm{M}$ inhibitor the increase of temperature didn't affect the potential, $\mathrm{E}_{\text {cor }}$ were
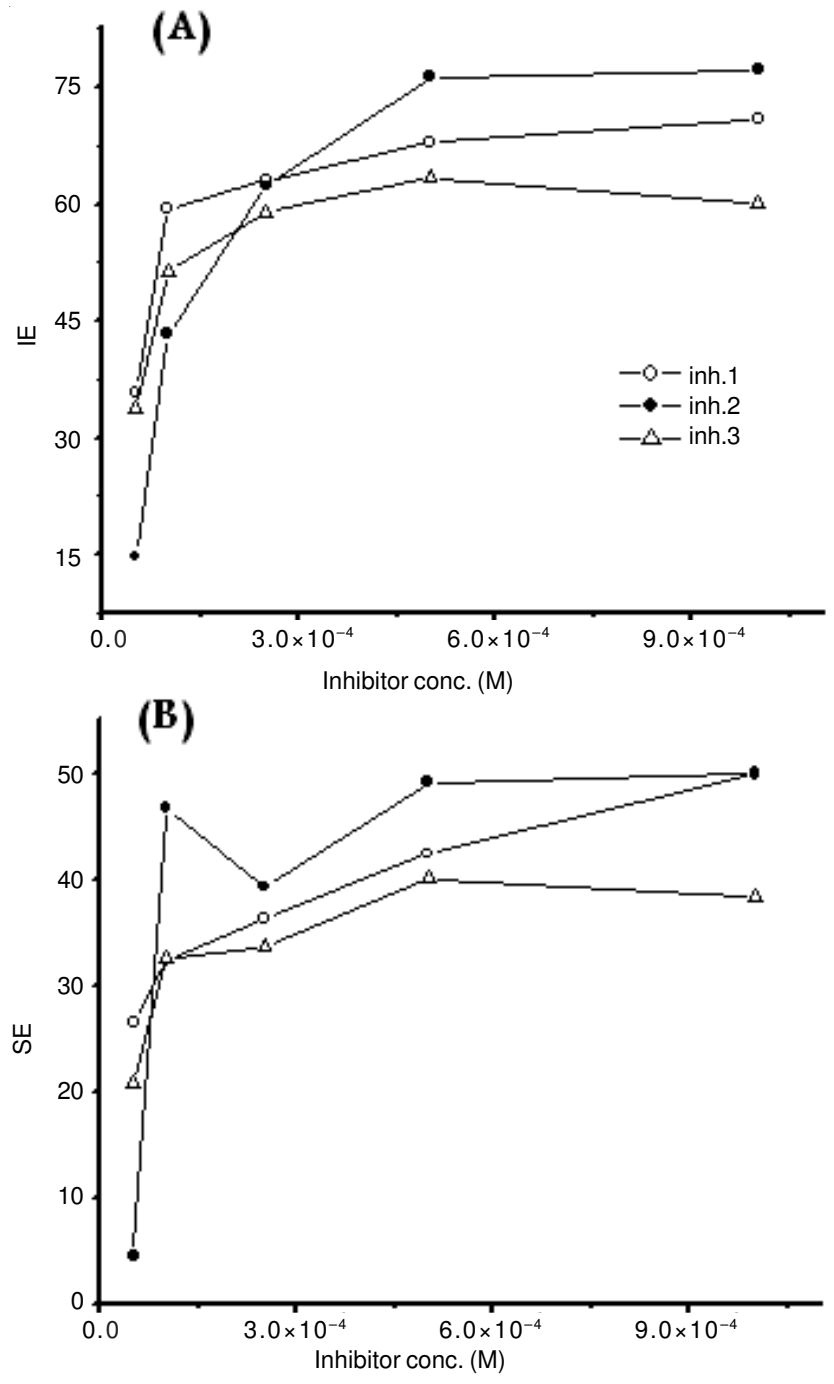

Fig. 3. Inhibition efficiency calculated from $i_{\text {cor }}(A)$ and $i_{\text {crit }}(B)$ against the concentration for $\mathrm{TMdPyBr}_{2}(\mathbf{O}), \mathrm{HMdPyBr}_{2}(\mathbf{\bullet})$ and $\mathrm{MPhdPyCl}_{2}$ $(\Delta)$

$-480,-468$ and $-490 \mathrm{mV}$ at $30^{\circ} \mathrm{C}$ and $-478,-470$ and $-486 \mathrm{mV}$ at $50^{\circ} \mathrm{C}$ for $\mathrm{TMdPyBr}_{2}, \mathrm{HMdPyBr}_{2}$ and $\mathrm{MPhdPyCl}_{2}$, respectively. This reflects a strong adsorption of the inhibitors on the stainless steel surface. The changes of the inhibition efficiency and supression efficiency with temperature are shown in Table- 2 . The inhibition efficiency generally decreased with increasing temperature in presence of $\mathrm{TMdPyBr}_{2}$ but it increased in case of $\mathrm{HMdPyBr}_{2}$ and $\mathrm{MPhdPyCl}_{2}$ up to maximum value at $45^{\circ} \mathrm{C}$. At this temperature the $\mathrm{HMdPyBr}_{2}$ exerted efficiency $85 \%$, the highest value in this study.

The supression efficiency, in presence of $1 \times 10^{-3} \mathrm{M}$ $\mathrm{HMdPyBr}_{2}$, increased with increasing temperature and reached

TABLE-2

INHIBITION EFFICIENCIES (FROM TAFEL LINES AND EIS) AND SUPPRESSION EFFICIENCIES FOR THE INHIBITORS

\begin{tabular}{|c|c|c|c|c|c|c|c|c|c|}
\hline \multirow{2}{*}{$\mathrm{t}\left({ }^{\circ} \mathrm{C}\right)$} & \multicolumn{3}{|c|}{$\mathrm{TMdPyBr}_{2}$} & \multicolumn{3}{|c|}{$\mathrm{HMdPyBr}_{2}$} & \multicolumn{3}{|c|}{$\mathrm{MPhdPyCl}_{2}$} \\
\hline & \multicolumn{2}{|c|}{ IE } & \multirow{2}{*}{$\frac{\mathrm{SE}}{-}$} & \multicolumn{2}{|c|}{ IE } & \multirow{2}{*}{$\frac{\text { SE }}{-}$} & \multicolumn{2}{|c|}{ IE } & \multirow{2}{*}{$\frac{\mathrm{SE}}{-}$} \\
\hline- & Tafel & EIS & & Tafel & EIS & & Tafel & EIS & \\
\hline 30 & 76.0 & 66.50 & 49.8 & 71.3 & 70.4 & 50.0 & 60 & 38 & 38.4 \\
\hline 35 & 61.1 & 84.03 & 46.3 & 75.8 & 91.1 & 58.6 & 54.2 & 65 & 33.9 \\
\hline 40 & 62.3 & 88.20 & 46.7 & 84.6 & 94.3 & 62.1 & 65 & 72.3 & 39.8 \\
\hline 45 & 48.4 & 83.30 & 31.5 & 84.7 & 94.7 & 54.6 & 76 & 74.6 & 31.2 \\
\hline 50 & 40.7 & 80.00 & 35.0 & 79.4 & 95.2 & 52.2 & 68.7 & 79.8 & 30.8 \\
\hline
\end{tabular}




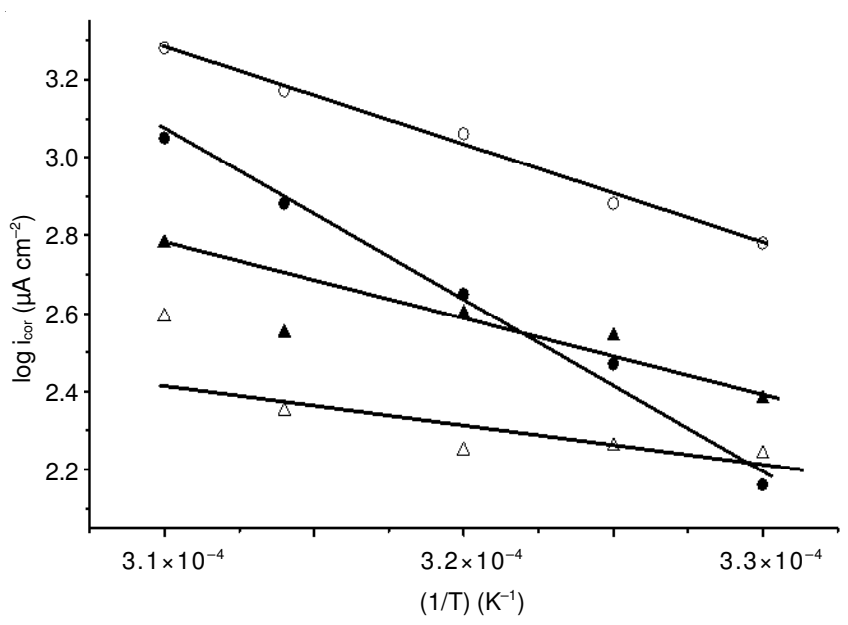

Fig. 4. Arrhenius plots for the corrosion of the SS in $0.1 \mathrm{M} \mathrm{HCl}(\mathbf{O})$ and in presence of $1 \times 10^{-3} \mathrm{M}$ of $\mathrm{TMdPyBr}_{2}(\bullet), \mathrm{HMdPyBr}_{2}(\boldsymbol{\Delta})$ or $\mathrm{MPhdPyCl}_{2}($

maximum value $(62.1 \%)$ at $40{ }^{\circ} \mathrm{C}$, as shown in Table-2. In case of $\mathrm{TMdPyBr}_{2}$ or $\mathrm{MPhdPyCl}_{2}$ the supression efficiency didn't significantly influence by temperature, it decreased slightly after $40{ }^{\circ} \mathrm{C}$. This indicates that the passivation of stainless steel is improved by these inhibitors up to $40{ }^{\circ} \mathrm{C}$. The dependence of corrosion current density on the temperature can be expressed with Arrhenius equation:

$$
\log i_{\text {corr }}=\log \lambda-\left(\frac{E_{a}}{2.303 R T}\right)
$$

where $\lambda$ the pre-exponential factor and $\mathrm{E}_{\mathrm{a}}$ is the apparent activation energy of the corrosion process. Plotting of $\log \mathrm{i}_{\text {cor }}$ versus $1 / \mathrm{T}$ produced a straight line (Fig. 4). Values of $\mathrm{E}_{\mathrm{a}}$ for stainless steel in $0.1 \mathrm{M} \mathrm{HCl}$ in the absence and presence of $1 \times 10^{-3} \mathrm{M}$ inhibitor were determined from the produced lines. The linear regression coefficients were $0.995,0.995,0.83$ and 0.87 in case of the pure solution and in presence of $\mathrm{TMdPyBr}_{2}$, $\mathrm{HMdPyBr}_{2}$ and $\mathrm{MPhdPyCl}_{2}$, respectively. The values of $\mathrm{E}_{\mathrm{a}}$ in the pure solution and in presence of $\mathrm{TMdPyBr}_{2}, \mathrm{HMdPyBr}_{2}$ and $\mathrm{MPhdPyCl}_{2}$ were 48.35, 82.14, 29.1 and $29.58 \mathrm{k} \mathrm{J} \mathrm{mol}^{-1}$, respectively. The higher value of $\mathrm{E}_{\mathrm{a}}$ obtained in presence of $\mathrm{TMdPyBr}_{2}$, in comparsion with that of the blank solution and the general decrease of the inhibition efficiency with increasing temperature is indicative for physical adsorption (electrostatic attraction between charged molecules and the charged metal surface) of this compound. The lower values of $E_{a}$ in the presence of other inhibitors and the general increase of their inhibition efficiency with increasing temperature are indicative for chemisorption (interaction of unshared electron pairs in the adsorbed molecule with the metal) on the steel surface.

Adsorption isotherm: The fraction of surface coverage $(\theta)$ by inhibitor molecules can be calculated from the equation:

$$
q=\left[1-\left(\frac{i_{\text {corr }}}{i_{\text {corr }}^{o}}\right)\right]
$$

In an attempt to find the most suitable adsorption isotherm(s), $\theta$ was subjected to various adsorption isotherms. For all inhibitors, the experimental results were found to fit Langmuir isotherm for monolayer chemisorptions where $\theta$ and $\mathrm{C}$ (inhibitor's concentration in the bulk of the solution) are related to each other via the equation:

$$
q=\frac{K C}{(1+K C)}
$$

Rearrangement gives

$$
\frac{\mathrm{C}}{\theta}=\left(\frac{1}{\mathrm{~K}}\right)+\mathrm{C}
$$

$\mathrm{K}$ is the equilibrium constant of the adsorption process. Plotting of $\mathrm{C} / \theta$ against $\mathrm{C}$ gives a straight line with linear regression coefficient $0.997 \pm 0.001$ for the three inhibitors; Fig. 5 shows the plot of $\mathrm{MPhdPyCl}_{2}$. The slopes of the straight lines were 1.36, 1.30 and 1.60 for $\mathrm{TMdPyBr}_{2}, \mathrm{HMdPyBr}_{2}$ and $\mathrm{MPhdPyCl}_{2}$, respectively. It is larger than one, particularly for $\mathrm{MPhdPyCl}_{2}$, indicating the interaction between the adsorbed molecules and/or related to steric hindrance factor ${ }^{20}$. The calculated $\mathrm{K}$ values are $1.02 \times 10^{4}, 1.43 \times 10^{4}$ and $2.95 \times 10^{4}$ for $\mathrm{TMdPyBr}_{2}, \mathrm{HMdPyBr}_{2}$ and $\mathrm{MPhdPyCl}_{2}$, respectively. This indicating the adsorption process increased in the order $\mathrm{TMdPyBr}_{2}<\mathrm{HMdPyBr}_{2}<\mathrm{MPhdPyCl}_{2}$.

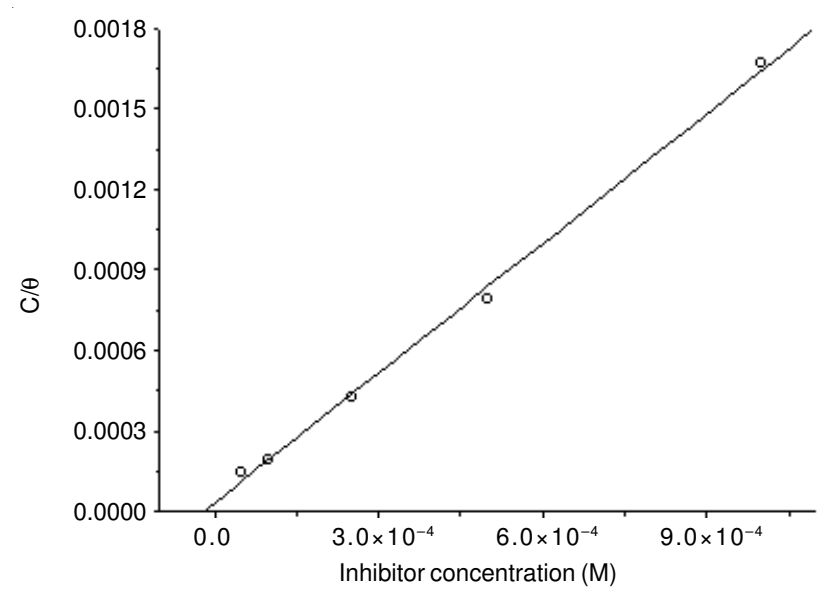

Fig. 5. Langmuir adsorption isotherm of $\mathrm{MPhdPyCl}_{2}$ on the stainless steel surface

The constant $\mathrm{K}$ is related to the standard free energy of adsorption $\left(\Delta \mathrm{G}_{\text {ads }}^{\mathrm{o}}\right)$ by the equation:

$$
\mathrm{K}=\left(\frac{1}{55.5}\right) \exp \left(-\frac{\Delta \mathrm{G}^{\mathrm{o}}{ }_{\text {ads }}}{\mathrm{RT}}\right)
$$

where $\mathrm{R}$ is the gas constant and $\mathrm{T}$ is the absolute temperature. For the investigated inhibitors, $\Delta \mathrm{G}_{\text {ads }}^{\mathbf{o}}$ values are $-33.35,-34.22$ and $-36.05 \mathrm{~kJ} \mathrm{~mol}^{-1}$ for $\mathrm{TMdPyBr}_{2}, \mathrm{HMdPyBr}_{2}$ and $\mathrm{MPhdPyCl}_{2}$, respectively. Generally, values of $\Delta \mathrm{G}_{\text {ads }}^{\mathrm{o}}$ around $-20 \mathrm{~kJ} / \mathrm{mol}$ or lower are consistent with electrostatic interaction between the charged molecules and the charged metal surface (physisorption) while those around $-40 \mathrm{~kJ} / \mathrm{mol}$ or higher involve charge sharing or charge transfer from the organic molecules to the metal surface to form a coordinate type bond (chemisorption) ${ }^{21}$. It is suggested that the chemical adsorption for the investigated inhibitors increases in the order $\mathrm{TMdPyBr}_{2}$ $<\mathrm{HMdPyBr}_{2}<\mathrm{MPhdPyCl}_{2}$.

Impedance measurement: Electrochemical impedance measurements were performed for 430 stainless steel in aerated $0.1 \mathrm{M} \mathrm{HCl}$ and in presence of the additives. The measurements were carried out at open circuit potential after $0.5 \mathrm{~h}$ of electrode immersion in which the steady state potential was established. 
The electrochemical impedance spectra obtained in pure acid solution and at any studied temperature consist of two capacitive semicircles (two well-defined time-constants in Bode-phase format), large one at high and intermediate frequencies and followed by small one at low frequencies as shown in Fig. 6A. The presence of two time constants in the spectra is characteristic for rough and porous electrode or inhomogeneous film on the metal surface ${ }^{22}$. Mansfeld ${ }^{23}$ reported that the initiation of small amounts of pits on the metal surface produces significant changes in the impedance spectra at low measured frequencies. It is explained for the spectra in Fig. 6A that the first capacitive semicircle is related to charge transfer resistance and capacity of electric double layer while the second semi-circuit is attributed to presence of pits area on the steel surface ${ }^{24}$. The decrease of the diameter of the capacitive loop with increasing the temperature indicates the increase of corrosion as shown in Fig. 6A. Well fitting for these spectra, as shown in Fig. 6B, is obtained by using an equivalent circuit shown in Fig. 7A. The circuit is composed of solution resistance $\left(\mathrm{R}_{\mathrm{s}}\right)$, capacitance of electric double layer (as constant phase element, CPE1), charge transfer resistance $\left(R_{p}\right)$ and an impedance is related to pits area (consisting of capacitance, CPE2 and resistance, R).
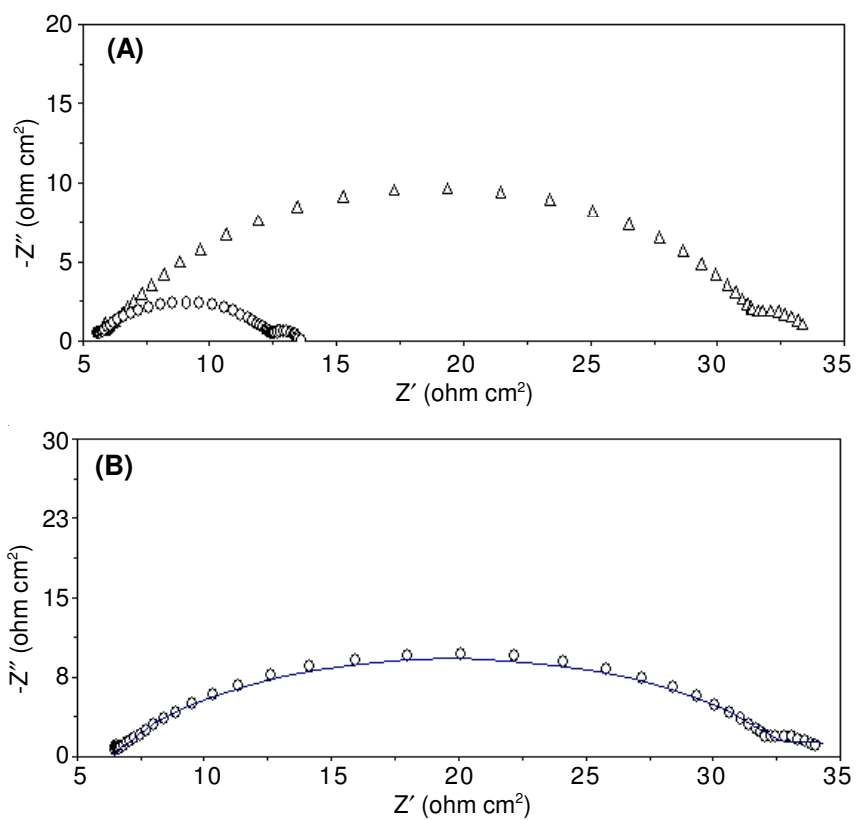

Fig. 6. (A) Nyquist plots for the corrosion of the stainless steel in $0.1 \mathrm{M}$ $\mathrm{HCl}$ solution at $30^{\circ}(\boldsymbol{\Delta})$ and $35^{\circ} \mathrm{C}(\mathbf{O})$. (B) Fitting for the spectra which recorded at $30^{\circ}$

In presence of the additives at $30^{\circ} \mathrm{C}$, both $\mathrm{TMdPyBr}_{2}$ and $\mathrm{HMdPyBr}_{2}$ produced one capacitive loop (one time-constant in Bode-phase representation), except the first concentration of $\mathrm{TMdPyBr}_{2}$ showed second semi-circuit and the diameter of the capacitive loop increased with increasing the inhibitor concentration (Fig. 8). It is indicating that these compounds, particularly $\mathrm{HMdPyBr}_{2}$, retarded both the general corrosion and the initiation of pitting corrosion of SS. These spectra are fitted well with the simple equivalent circuit shown in Fig. 7B.

In case of the first three concentrations of $\mathrm{MPhdPyCl}_{2}$ electrochemical impedance spectra show two capacitive semicircles, large one and followed by very small one at low frequencies. The second semicircle disappeared in presence
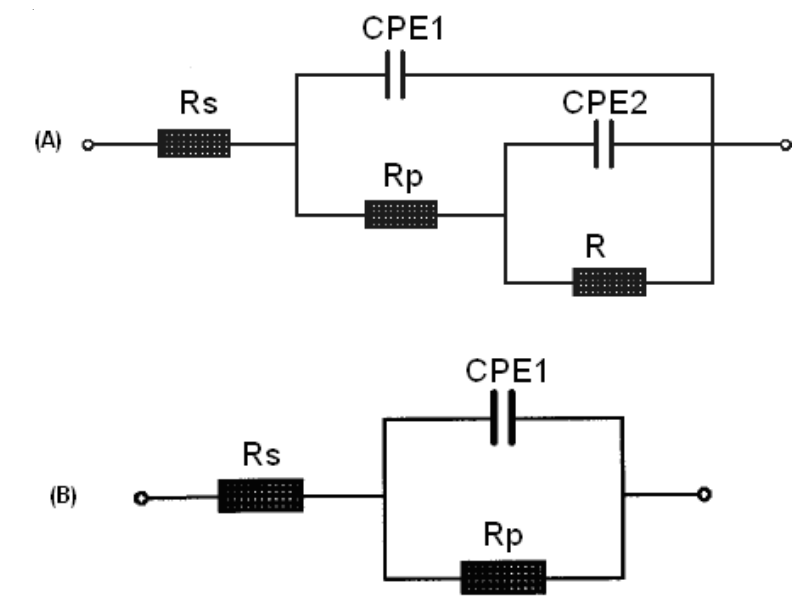

Fig. 7. Equivalent circuits represent (A) pitting corrosion model (B) general corrosion model

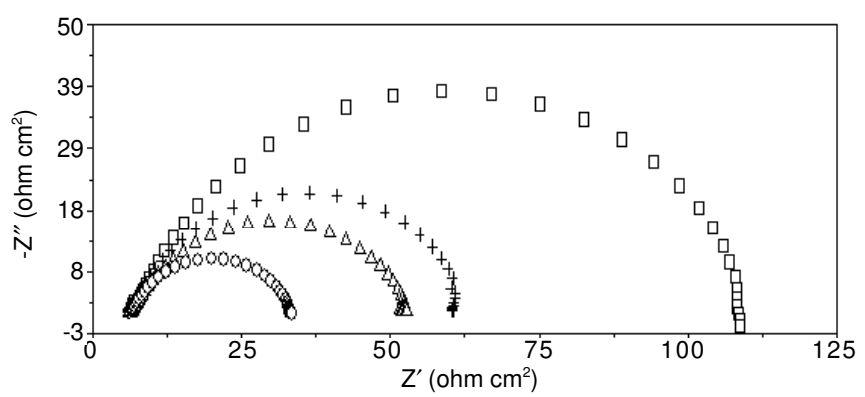

Fig. 8. Nyquist plots for the corrosion of the stainless steel in $0.1 \mathrm{M} \mathrm{HCl}$ solution containing $5 \times 10^{-5} \mathrm{M}(\mathbf{O}), 1 \times 10^{-4} \mathrm{M}(\boldsymbol{\Delta}), 2.5 \times 10^{-4} \mathrm{M}(+)$ and $5 \times 10^{-4} \mathrm{M}(\mathbf{\square}) \mathrm{HMdPyBr}_{2}$ at $30^{\circ} \mathrm{C}$

of the higher concentrations $=5 \times 10^{-4} \mathrm{M}$ (Fig. 9). It is indicated that this compound inhibited the general corrosion with lower efficiency than that of $\mathrm{HMdPyBr}_{2}$ and failed to inhibit the pitting corrosion at its first concentrations. Two capacitive semicircles were obtained at OCP for iron in $1 \mathrm{M} \mathrm{HCl}$ containing phosphonium compounds which showed low inhibition or acceleration. The second semi-circuit was attributed to formation of an incomplete layer on the iron surface and this situation can lead to acceleration of the corrosion ${ }^{25}$.

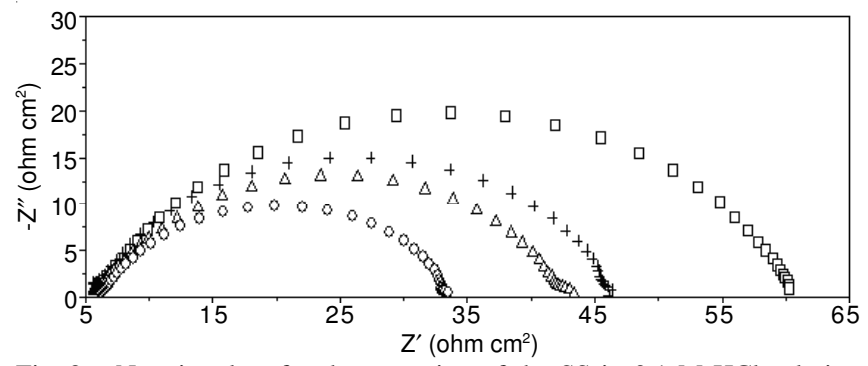

Fig. 9. Nyquist plots for the corrosion of the SS in $0.1 \mathrm{M} \mathrm{HCl}$ solution containing $5 \times 10^{-5} \mathrm{M}(\mathbf{O}), 1 \times 10^{-4} \mathrm{M}(\boldsymbol{\Delta}), 2.5 \times 10^{-4} \mathrm{M}(+)$ and $5 \times$ $10^{-4} \mathrm{M}$ (ㅁ) $\mathrm{MPhdPyCl}_{2}$ at $30^{\circ} \mathrm{C}$

At $1 \times 10^{-3} \mathrm{M}$ both $\mathrm{TMdPyBr}_{2}$ and $\mathrm{HMdPyBr}_{2}$ gave one capacitive loop while $\mathrm{MPhdPyCl}_{2}$ gave two capacitive loops in all measurements at higher temperatures $\left(35-50{ }^{\circ} \mathrm{C}\right)$. This confirmed the good inhibition by $\mathrm{TMdPyBr}_{2}$ and $\mathrm{HMdPyBr}_{2}$ and the weak role of $\mathrm{MPhdPyCl}_{2}$ against the initiation of pitting corrosion in the aggressive condition. Fig. 10 shows representative electrochemical impedance spectra of the three 


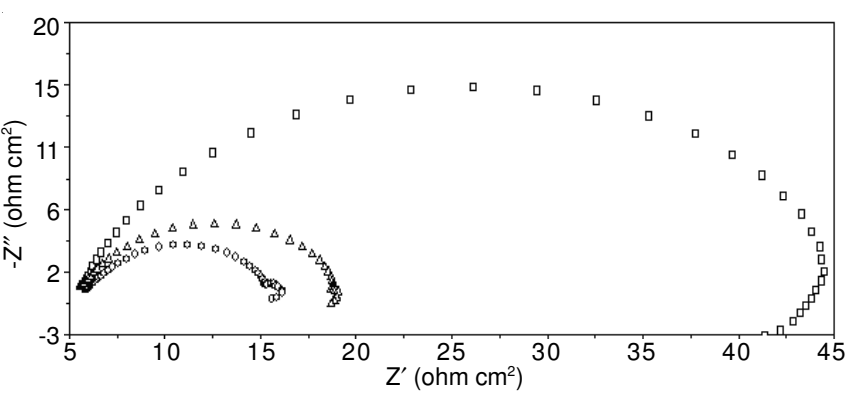

Fig. 10. Nyquist plots for the corrosion of the SS in $0.1 \mathrm{M} \mathrm{HCl}$ solution containing $1 \times 10^{-3} \mathrm{M}$ of $\mathrm{MPhdPyCl}_{2}(\mathbf{O}), \mathrm{TMdPyBr}_{2}(\boldsymbol{\Delta})$ and $\mathrm{HMdPyBr}_{2}(\square)$ at $50^{\circ} \mathrm{C}$

inhibitors at $50{ }^{\circ} \mathrm{C}$. An inductive loop is appeared at low frequency region in the spectra of all the investigated compounds. This has been determined for iron-based materials at $\mathrm{E}_{\mathrm{cor}}$ in acid media in the presence of inhibitors ${ }^{26}$.

Fig. 11 shows the inhibition efficiency calculated from $R_{p}$ values against the concentration for the three inhibitors at $30{ }^{\circ} \mathrm{C}$. Generally, there is agreement with that calculated from corrosion current (Fig. 3A). The maximum efficiency by $\mathrm{HMdPyBr}_{2}$ was $76.6 \%$ in presence of $5 \times 10^{-4} \mathrm{M}$ while by using polarization measurement it was $77.3 \%$ in presence of $1 \times 10^{-3} \mathrm{M}$. The inhibition efficiency calculated form electrochemical impedance at different temperature (Table-2) are also in agreement with the polarization results. $\mathrm{HMdPyBr}_{2}$ exhibited best inhibition efficiency among the studied compounds. There was general increasing of inhibition efficiency with temperature in presence of $\mathrm{HMdPyBr}_{2}$ and $\mathrm{MPhdPyCl}_{2}$ and reach the maximum values 95.2 and $79.8 \%$, respectively, at $50{ }^{\circ} \mathrm{C}\left(84.7\right.$ and $76 \%$, respectively, at $45^{\circ} \mathrm{C}$ by polarization measurement), respectively. These results confirm the chemisorption behaviour of these compounds. $\mathrm{TMdPyBr}_{2}$ shows maximum efficiency $\left(88.2 \%\right.$ ) at $40{ }^{\circ} \mathrm{C}$, the difference in its result from that by polarization measurement reflects that this compound is acted by physical and weak chemical adsorption.

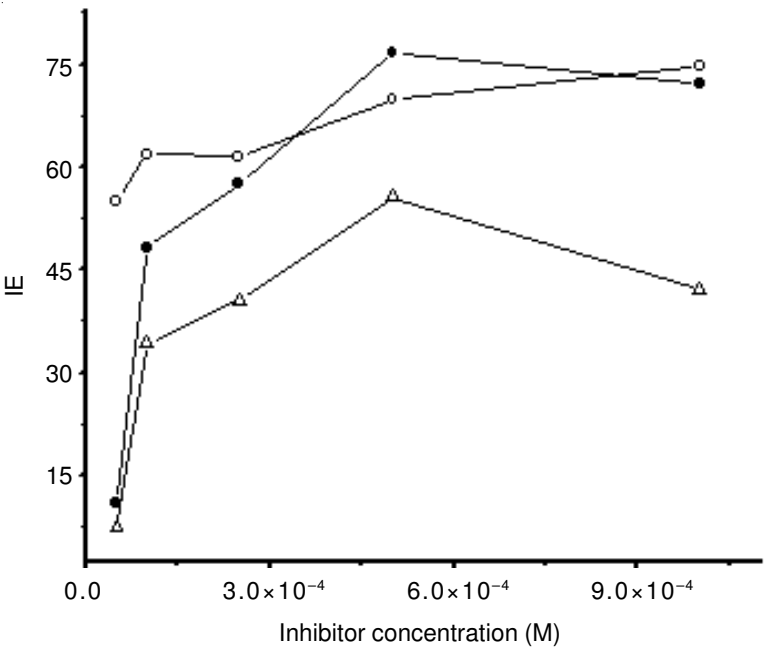

Fig. 11. Inhibition efficiency calculated from $\mathrm{R}_{\mathrm{p}}$ against the concentration for $\mathrm{TMdPyBr}_{2}(\mathbf{O}), \mathrm{HMdPyBr}_{2}(\mathbf{\bullet})$ and $\mathrm{MPhdPyCl}_{2}(\boldsymbol{\Delta})$

Microscopic study: Microscopic investigation of the steel surface after $0.5 \mathrm{~h}$ immersion in $0.1 \mathrm{M} \mathrm{HCl}$ solution at $45^{\circ} \mathrm{C}$ in absence and presence of $1 \times 10^{-3} \mathrm{M}$ additives are shown in
Fig. 12. It is clear that the stainless steel suffered from general and localized attack (image A) and the presence of $\mathrm{TMdPyBr}_{2}$ (image $\mathrm{B}$ ) or $\mathrm{HMdPyBr}_{2}$ (images $\mathrm{C}$ ) protected well the stainless steel surface. $\mathrm{MPhdPyCl}_{2}$ couldn't protect the stainless steel completely, some local attack is observed in the image D. This result is in quite reasonable agreement with the result of electrochemical methods.
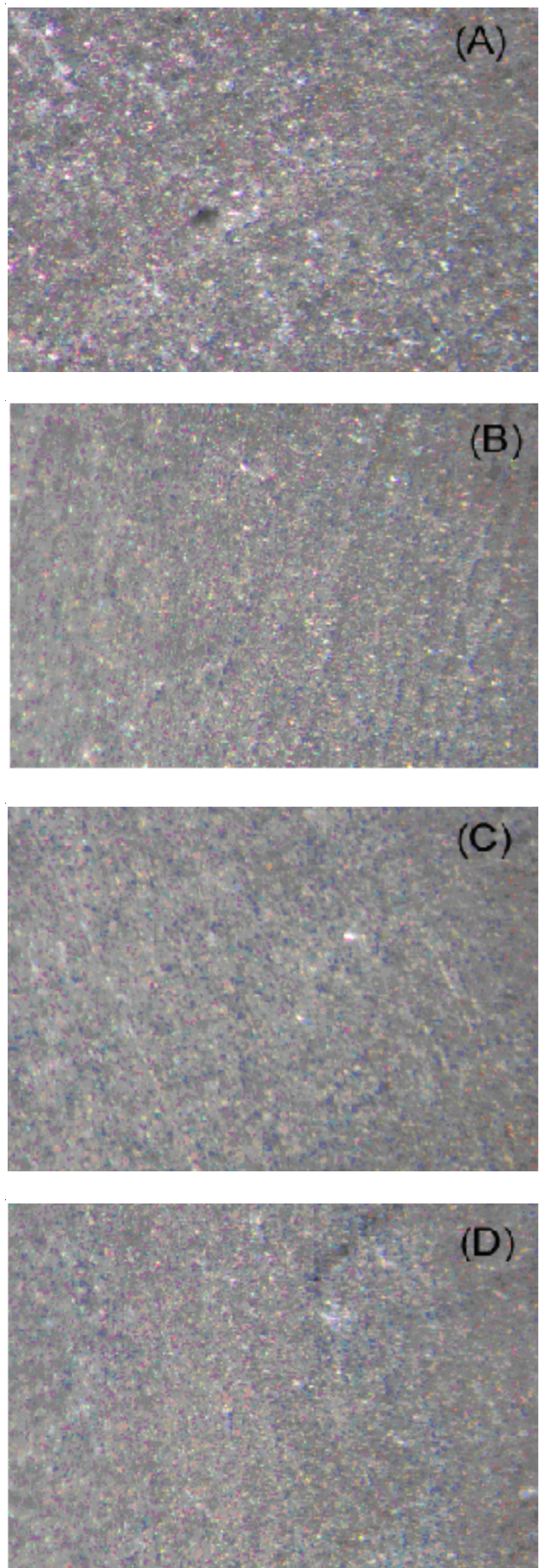

Fig. 12. Microscopic images after immersion of the $\mathrm{SS}$ in $0.1 \mathrm{M} \mathrm{HCl}$ solution in absence (A) and presence of $1 \times 10^{-3} \mathrm{MTMdPyBr}_{2}(\mathrm{~B}), \mathrm{HMdPyBr}_{2}$ (C) and $\mathrm{MPhdPyCl}_{2}$ (D) at $45^{\circ} \mathrm{C}$

Mechanism of inhibition: Adsorption process occurs by electrostatic forces between ionic charges or dipoles of the adsorbed species and the electric charge on the metal surface 
which can be expressed by its potential with respect to potential of zero charge (pzc). Also, the inhibitor molecules can be adsorbed onto the metal surface via the electron transfer from the adsorbed species to the vacant electron orbital of low energy in the metal to form a coordinate type of link ${ }^{11}$. It was explained that the surfactant molecules adsorb by its head (hydrophilic) directing its tail (hydrophobic) to the solution face leading to decrease in the corrosion rate ${ }^{12,27}$. It is suggested that the two ammonium groups and aromatic rings in the dipyridinium molecule can be adsorbed at the different sites on the metallic surface. The molecule is physically adsorbed via the two positively charged nitrogen atoms and the aromatic rings are parallel to the surface and the methyl group tail is extended away in the solution. This position is allowed for transfer of the $\pi$-electrons of the pyridine rings to the vacant electron orbital of low energy in the metal to form a coordinate type of link (chemical adsorption) ${ }^{18}$. The transformation from physical adsorption to chemical type can be occurred gradually ${ }^{28}$.

Delocalization of $\pi$ orbital in the pyridine ring may increase the positive charge on the nitrogen atom of the ring. In other side, the attached methyl groups increase the electron density of the aromatic rings while they may decrease the positive charge of the nitrogen atom. In other words, the attached methyl groups increase the chemisorption property of the dipyridinium molecule. Many arguments in this study prove that the higher methylated molecule $\mathrm{HMdPyBr}_{2}$ has strong chemisorption with the stainless steel surface while the lower methylated molecule $\mathrm{TMdPyBr}_{2}$ is acted by weaker chemical adsorption. The chemisorption type inhibitor is important for protection of the stainless steel particularly in aggressive solutions containing chloride ions. The blocking of the active sites on the surface by strong chemical adsorption of the inhibitor enhances the oxide film formation.

The chemical structure of $\mathrm{MPhdPyCl} \mathrm{C}_{2}$ molecule is different (Fig. 1) by presence of two methyl phenyl groups attached to the nitrogen atom. The presence of additional two benzene rings is expected to increase the covered area and the electronic interaction with the metal surface. $\mathrm{MPhdPyCl}_{2}$ caused low corrosion activation energy than that in pure medium and had largest $\mathrm{K}$ value and largest negative $\Delta \mathrm{G}_{\text {ads }}^{\mathrm{o}}$ value among the investigated compounds, indicating strong chemisorption of this compound. In our previous work ${ }^{18} \mathrm{MPhdPyCl}_{2}$ exhibited highest inhibition efficiency, among the same group inhibitors, for low carbon steel in $\mathrm{H}_{2} \mathrm{SO}_{4}$ solution. However, in this study, this inhibitor showed the lowest inhibition efficiency of stainless steel in $\mathrm{HCl}$ solution and weak inhibitor for pitting initiation. At higher concentration of this inhibitor a red-brown precipitate is formed on the steel surface at the open circuit potential as observed before ${ }^{18}$. This inhibitor, most likely, is exposed to irreversible reduction and deposited as precipitate on the electrode surface. Although the deposited layer enhanced the inhibition (secondary inhibition) of mild steel in sulfuric, it is inefficient against the pitting corrosion of the stainless steel. The secondary inhibition may be higher or lower than primary inhibition, depending on the effectiveness of the reaction products $^{29}$.

In this study $\mathrm{HMdPyBr}_{2}$ is superior inhibitor among the studied compound for both the general and localized corrosion of stainless steel in $\mathrm{HCl}$ solution. However, this compound exhibited least inhibition efficiency for corrosion of mild steel in $\mathrm{H}_{2} \mathrm{SO}_{4}$ and it was attributed to influence of steric hindrance of the attached methyl groups on the adsorption of the molecule $^{16}$. But, why the steric hindrance doesn't influence in the stainless steel- $\mathrm{HCl}$ system. This is explained by the fact that the changes of the substrate metal and/or the type of aggressive electrolyte are significantly influenced on the adsorption process of the same inhibitor ${ }^{29}$.

\section{Conclusion}

The used dipyridinium salts work as mixed type inhibitors with dominant anodic against the corrosion of the stainless steel in $0.1 \mathrm{M} \mathrm{HCl}$ solution. They do not alter the mechanism of either hydrogen evolution or steel dissolution reactions. The values of $\mathrm{E}_{\mathrm{a}}$ in absence and presence of $\mathrm{TMdPyBr}_{2}, \mathrm{HMdPyBr}_{2}$ and $\mathrm{MPhdPyCl}_{2}$ were 48.35, 82.14, 29.1 and $29.58 \mathrm{~kJ} \mathrm{~mol}^{-1}$, respectively. The adsorption of these compounds on the steel surface was found to obey Langmuir adsorption isotherm. The calculated $\mathrm{K}$ values were $1.02 \times 10^{4}, 1.43 \times 10^{4}$ and $2.95 \times 10^{4}$ and $\Delta \mathrm{G}_{\text {ads }}^{\mathrm{o}}$ values were $-33.35,-34.22$ and $-36.05 \mathrm{~kJ} \mathrm{~mol}^{-1}$ for $\mathrm{TMdPyBr}_{2}, \mathrm{HMdPyBr}_{2}$ and $\mathrm{MPhdPyCl}_{2}$, respectively. These arguments suggested that the chemical adsorption for the investigated inhibitors increases in the order $\mathrm{TMdPyBr}_{2}<$ $\mathrm{HMdPyBr}_{2}<\mathrm{MPhdPyCl}_{2}$. However, the inhibition efficiency and supression efficiency increased in the order $\mathrm{MPhdPyCl}_{2}$ $<\mathrm{TMdPyBr}_{2}<\mathrm{HMdPyBr}_{2}$. The appearance of second capacitive semicircle in the low frequencies region of the Nyquist plot was attributed to presence of pits on the steel surface. Both $\mathrm{TMdPyBr}_{2}$ and $\mathrm{HMdPyBr}_{2}$ inhibit the pitting initiation while $\mathrm{MPhdPyCl}_{2}$ is less efficient inhibitor against the pitting. The optical microscopic investigation is in quite reasonable agreement with the result of electrochemical methods. The superiority for $\mathrm{HMdPyBr}_{2}$ as inhibitor was attributed to the higher attached methyl groups which increase the chemisorption property of the dipyridinium molecule. In spite of its chemisorption on the stainless steel surface, $\mathrm{MPhdPyCl}_{2}$ showed the lowest inhibition efficiency. This inhibitor, most likely, is exposed to irreversible reduction and deposited as precipitate on the electrode surface.

\section{ACKNOWLEDGEMENTS}

The authors are grateful to Saudi Basic Industries Corporation (SABIC) and to the Research and Development Center in the King Abdulaziz University under contract No. MS/9/4 for financial support of this work.

\section{REFERENCES}

1. J.W. Schultze and M.M. Lohrengel, Electrochim. Acta, 45, 2499 (2000).

2. H.M. El-Kashlan, Asian J. Chem., 23, 5235 (2011).

3. T. Yanardag, S. Özbay, S. Dinçer and A.A. Aksüt, Asian J. Chem., 24, 47 (2012).

4. S.A.M. Refaey, F. Taha and A.M. Abd El-Malak, Appl. Surf. Sci., 242, 114 (2005).

5. F. Bentiss, M. Lagrenee, M. Trainsel and J.C. Hornez, Corros. Sci., 41, 789 (1999).

6. A. Popova, M. Christov and A. Vasilev, Corros. Sci., 49, 3276 (2007).

7. A. Popova, M. Christov and A. Vasilev, Corros. Sci., 49, 3290 (2007).

8. M.S. Abdel-Aal, M. Th. Makhlof and A.A. Hermas, Proceedings of The Seventh European Symposium on Corrosion Inhibitor, Ann. Univ. Ferrara, N.S. sezV, Suppl. No. 9, p. 1143 (1990).

9. M.H. Wahdan, A.A. Hermas and M.S. Morad, Mater. Chem. Phys., 76, 111 (2002). 
10. A.A. Hermas, M.S. Morad and M.H. Wahdan, J. Appl. Electrochem., 34, 95 (2004).

11. M.A. Migahed, Mater. Chem. Phys., 93, 48 (2005).

12. M.M. Saleh, Mater. Chem. Phys., 98, 83 (2006).

13. M. El Achouri, S. Kertit, H.M. Gouttaya, B. Nciri, Y. Bensouda, L. Perez, M.R. Infante and K. Elkacemi, Prog. Org. Coat., 43, 267 (2001).

14. M. El Achouri, M.R. Infante, F. Izquierdo, S. Kertit, H.M. Gouttaya and B. Nciri, Corros. Sci., 43, 19 (2001).

15. P. Stipa, Spectrochim. Acta A, 64, 653 (2006).

16. J.-Y. Ock, H.-K. Shin, Y.-S. Kwon and J. Miyake, Colloid. Surf. A, 257-258, 351 (2005)

17. S.G. Aziz, A.Y. Obaid, A.O. Alyoubi and A.A. Abdel Fattah, Corros. Preven. Control, 44, 179 (1997).

18. M.S. Morad, A.A. Hermas, A.Y. Obaid and A.H. Qusti, J. Appl. Electrochem., 38, 1301 (2008).

19. S.Z. Yao, X.H. Jiang, L.M. Zhou, Y.J. Lv and X.Q. Hu, Mater. Chem. Phys., 104, 301 (2007)
20. M.S. Morad, J. Appl. Electrochem., 29, 619 (1999).

21. M. Lebrini, M. Lagrenee, H. Vezin, M. Traisnel and F. Bentiss, Corros. Sci., 49, 2254 (2007).

22. T. Hong and W.P. Jepson, Corros. Sci., 43, 1839 (2001); M.C. Li, C.L. Zeng, S.Z. Luo, J.N. Shen, H.C. Lin and C.N. Cao, Electrochim. Acta, 48, 1735 (2003).

23. F. Mansfeld, Electrochim. Acta, 35, 1533 (1990).

24. H. Shih and F. Mansfeld, Corrosion, 45, 610 (1989).

25. K.F. Khaled, Appl. Surf. Sci., 230, 307 (2004).

26. F. Mansfeld, An Introduction to Electrochemical Impedance Measurement, Technical Report No. 26, Part No.: BTR026, Solartron Limited, May, pp. 1-14 (1999).

27. R. Zyauya and J.L. Dawson, J. Appl. Electrochem., 24, 943 (1994).

28. S.A. Abd El-Maksoud and A.S. Fouda, Mater. Chem. Phys., 93, 84 (2005).

29. G. Trabanelli, In ed.: F. Mansfeld, Corrosion Inhibitors, in Corrosion Mechanisms, Marcel Dekker, Inc. New York, p. 119 (1989). 